\title{
Non-digestible oligosaccharides and calcium absorption in girls with adequate calcium intakes ${ }^{\dagger}$
}

\author{
I. J. Griffin ${ }^{1,2 *}$, P. M. Davila ${ }^{1}$ and S. A. Abrams ${ }^{1,2}$ \\ ${ }^{1}$ USDA/ARS Children's Nutrition Research Center, Baylor College of Medicine, 1100 Bates Street, Houston, TX 77030, USA \\ ${ }^{2}$ Section of Neonatology, Department of Pediatrics, Baylor College of Medicine, Houston, TX 77030, USA
}

\begin{abstract}
Non-digestible oligosaccharides such as inulin and oligofructose have been shown to consistently increase calcium absorption in experimental animals, but data in humans are less clearcut. The objective of this study was to assess the effect of $8 \mathrm{~g} / \mathrm{d}$ of oligofructose or a mixture of inulin and oligofructose on calcium absorption in girls at or near menarche. A total of fiftynine subjects were studied using a balanced, randomized, cross-over design. They received, in random order, $8 \mathrm{~g} / \mathrm{d}$ placebo (sucrose), oligofructose or the mixture inulin+oligofructose for 3 weeks, separated by a 2 -week washout period. Throughout the study, subjects consumed a total of approximately $1500 \mathrm{mg} / \mathrm{d}$ dietary calcium, by adding two glasses of calcium-fortified orange juice to their diet. Four grams of placebo, oligofructose or the mixture inulin+oligofructose was added to each glass of orange juice immediately before it was consumed. At the end of each 3-week adaptation period, calcium absorption was measured, using a dual stable isotope technique, from the cumulative fractional excretion of an oral and an intravenous tracer over 48 hours. Calcium absorption was significantly higher in the group receiving the inulin+oligofructose mixture than in the placebo group $(38.2 \pm 9.8 \%$ v. $32.3 \pm 9.8 \% ; P=0.01)$, but no significant difference was seen between the oligofructose group and the placebo group $(31.8 \pm 9.3 \%$ v. $31.8 \pm 10.0 \%, P=\mathrm{NS})$. We conclude that modest intakes of an inulin+oligofructose mixture increases calcium absorption in girls at or near menarche.
\end{abstract}

Calcium absorption: Non-digestible oligosaccharides: Oligofructose: Inulin: Prebiotics: Stable isotope

\section{Introduction}

Maintenance of an adequate calcium intake at or near puberty is essential for the development of optimal peak bone mass (Matkovic, 1992) An adequate calcium intake during this pivotal time period is vital for optimum bone mineral accretion (Chan, 1991; Nieves et al. 1995). Interventions aimed at preventing the morbidity and mortality associated with osteoporosis may, therefore, best be aimed at this vulnerable age group (Matkovic, 1992). Despite the importance of an adequate calcium intake during this period, self-selected diets of children during this stage typically provide insufficient calcium (Eck \& HackettRenner, 1992), leading to inadequate calcium retention (Abrams \& Stuff, 1994).

There has been increasing interest in the effect of prebiotic non-digestible oligosaccharides as modifiers of mineral absorption in animals (Brommage et al. 1993; Delzenne et al. 1995; Rémésy et al. 1993) and humans (Roberfroid, 1999; Van Loo et al. 1999). These compounds resist digestion by human alimentary enzymes, and undergo fermentation in the large intestine (Van Loo et al. 1999). It is speculated that the volatile short-chain fatty acids produced by this fermentation lower cecal $\mathrm{pH}$, increase calcium concentration in the liquid phase of the cecal contents, and increase colonic absorption of calcium (Greger, 1999; Schulz et al. 1993). They may also have trophic effects in the gastrointestinal tract, which may increase calcium absorption either in the colon or throughout the entire gut (Chonan \& Watanuki, 1995; Greger, 1999; Rémésy et al. 1993).

The most widely studied non-digestible oligosaccharides

${ }^{\dagger}$ Supported in part with federal funds from the USDA/ARS under Cooperative Agreement No. 58-6250-6-001. This work is a publication of the U.S. Department of Agriculture (USDA)/Agricultural Research Service (ARS) Children's Nutrition Research Center, Department of Pediatrics, Baylor College of Medicine and Texas Children's Hospital, Houston, Texas. Contents of this publication do not necessarily reflect the views or policies of the USDA, nor does mention of trade names, commercial products, or organizations imply endorsement by the U.S. Government. This study was funded, in part, by ORAFTI, Tienen, Belgium.

Note: For the definition of the terms inulin and oligofructose please refer to the introductory paper (p. S139) and its footnote.

* Corresponding author: Dr I. Griffin, fax +1 713 798-7119, email igriffin@neo.bcm.tmc.edu 
in humans are inulin and oligofructose, which are naturally occurring components of the Western diet (Van Loo et al. 1995; Moshfegh et al. 1999). Human studies examining their effect on calcium absorption have been contradictory. Two studies have shown a beneficial effect of $40 \mathrm{~g} / \mathrm{d}$ inulin (Coudray et al. 1997) or $15 \mathrm{~g} / \mathrm{d}$ oligofructose (van den Heuvel et al. 1999) on calcium absorption in young men and adolescent boys on modest calcium intakes. A third study, however, found no effect of $15 \mathrm{~g} / \mathrm{d}$ of inulin, oligofructose or galacto-oligosaccharides on calcium absorption in a similar population (van den Heuvel et al. 1998). These discrepant findings may be due to methodological differences (Coudray \& Fairweather-Tait, 1998) or due to a type II error, as all the studies were relatively small.

All three previous studies involved male subjects on moderate calcium intakes (approximately $800 \mathrm{mg} / \mathrm{d}$ ), where calcium retention can be increased significantly by increasing calcium intake (Matkovic \& Heaney, 1992). In children at or near puberty calcium retention appears to reach a maximum at an intake of about $1200 \mathrm{mg} / \mathrm{d}$; calcium intakes above this threshold do not seem to lead to increased calcium retention (Matkovic \& Heaney, 1992). It is not known whether non-digestible oligosaccharides will increase calcium absorption at higher levels of calcium intake. Further, because previous studies have examined the effect of relatively large doses of these ingredients on calcium absorption, it is unclear whether significant increases in calcium absorption can be achieved at lower intakes.

The object of this study was, therefore, to examine the effect of relatively modest intakes of oligofructose and a mixture of oligofructose and inulin, on calcium absorption in a large sample of girls at or near menarche, with calcium intakes approximating the currently recommended dietary intake.

\section{Materials and methods}

Sixty healthy girls, 11.0-13.9 years of age, were recruited from the greater Houston area by public advertisement. Subjects were interviewed by a pediatric dietician prior to enrolment, and calcium intake was estimated using a food frequency questionnaire. Only subjects with a habitual calcium intake between 500 and $1400 \mathrm{mg} / \mathrm{d}$ were considered eligible for the study. Subjects were excluded from the study if they had chronic gastrointestinal disease, renal failure, or disorders of calcium homeostasis; were taking prescription medications (including oral contraceptives); smoked; or weighed more than the ninetieth percentile for age.

Subjects were studied using a randomized, double-blind, cross-over design. Subjects were randomized to receive two 4-g servings of non-digestible oligosaccharides daily for 3 weeks and two 4-g servings of placebo daily for 3 weeks, separated by a 2 -week washout period. The oligosaccharides and placebo were given in random order, and investigators were blinded to the treatment assignment. Two similar protocols were carried out simultaneously. In Protocol I, the non-digestible oligosaccharide used was chicory oligofructose (Raftilose ${ }^{\circledR}$ P95, Orafti, Tienen, Belgium); Protocol II used an inulin+oligofructose mixture
(Raftilose ${ }^{\circledR}$ Synergy1, Orafti, Tienen, Belgium). In both protocols, the placebo (sucrose) was packaged and presented in a manner that was identical to that of the oligosaccharides.

Subjects were instructed to maintain a calcium intake aimed at providing a total of approximately $1200-1300 \mathrm{mg} / \mathrm{d}$ during the study period by consuming an 8-ounce glass of calcium-fortified orange juice with breakfast and with the evening meal, and an 8-ounce glass of milk, calcium-fortified orange juice or a serving of yogurt with the midday meal. The placebo (sucrose), oligofructose or the inulin+oligofructose mixture were provided as packets containing $4 \mathrm{~g}$ of carbohydrates. One packet was added to both the morning and evening glasses of orange juice and gently mixed until it dissolved completely. The same dietary regime was continued during the 2-week washout period, but without oligosaccharides or placebo added to the glasses of orange juice. During the third week of each study period, subjects kept a weighed dietary record involving two weekdays and one weekend day. Calcium intake was calculated from these records by a pediatric dietician using the Nutrition Data System for Research (version 4.02, University of Minnesota, Minneapolis, MN)

At the end of each 3-week study period, the subjects were admitted to the Metabolic Research Unit of the Children's Nutrition Research Center. Calcium absorption was measured using a double stable isotope method. All used and unused packets of the placebo, oligofructose or the inulin+oligofructose mixture were returned, and compliance was measured by a packet count.

\section{Measurement of calcium absorption}

Calcium absorption was measured using a modification of a previously validated dual-isotope methodology (Yergey et al. 1994; Yergey et al. 1990). On the morning of the study, subjects were admitted to the Metabolic Research Unit of the Children's Nutrition Research Center, and a baseline urine sample was collected. Subjects consumed a low-calcium breakfast and an 8-ounce glass of calciumfortified orange juice to which was added one packet of placebo, oligofructose or the inulin+oligofructose mixture and $10 \mu \mathrm{g}$ of ${ }^{46} \mathrm{Ca}$. The oligosaccharide was added immediately prior to consumption of the drink, and the ${ }^{46} \mathrm{Ca}$ $18-24 \mathrm{~h}$ earlier. Immediately after breakfast, $1.5 \mathrm{mg}$ of ${ }^{42} \mathrm{Ca}$ was infused intravenously over $3-5 \mathrm{~min}$. The midday meal contained approximately $400 \mathrm{mg}$ calcium in the form of calcium-fortified orange juice, milk or yogurt. The evening meal contained another serving of calcium-fortified orange juice, $10 \mu \mathrm{g}$ of ${ }^{46} \mathrm{Ca}$, and a packet of oligosaccharide or placebo. Immediately after the first dose of calcium isotopes was administered, a complete $48 \mathrm{~h}$ urine collection was begun. After the evening meal, subjects were discharged to their homes, where they completed the urine collection.

Stable isotopes were purchased from Oak Ridge National Laboratories (Oak Ridge, TN) as the carbonate salts. Aqueous solutions were prepared as previously described (Eastell et al. 1989) by the Pharmacy Department of Texas Children's Hospital, and tested for sterility 
and pyrogenicity prior to use. All isotopes were dispensed in medicinal syringes which were weighed before and after use, and the exact dose of isotope given was calculated from the change in weight. A complete $48 \mathrm{~h}$ urine collection was started immediately following the infusion of ${ }^{42} \mathrm{Ca}$. Samples were purified using an oxalate precipitation method (Yergey et al. 1980) and isotope ratios measured by thermal ionization magnetic sector mass spectrometry (Finnigan, MAT 261 Bremen, Germany). Isotope ratios were expressed with regard to the non-administered isotope ${ }^{43} \mathrm{Ca}$ and corrected for fractionation using the ratio of ${ }^{44} \mathrm{Ca}$ to ${ }^{43} \mathrm{Ca}$. Repeated blocks of ten scans were performed until the desired degree of precision was obtained. Calcium absorption was measured from the ratio of the fractional excretion of the oral and intravenous isotopes in the $48 \mathrm{~h}$ urine collection, as described elsewhere (Eastell et al. 1989; Yergey et al. 1980).

\section{Statistical analysis}

Based on previous studies, we had anticipated a mean calcium absorption of approximately $30 \%$, with a standard deviation of $8 \%$. We considered a $5 \%$ difference in calcium absorption to be the smallest clinically significant difference, so thirty subjects were required to have a $90 \%$ power $(\beta=0 \cdot 10)$ to detect this difference at a statistical significance of $P<0.05(\alpha=0.05)$.

The effect of oligofructose or the inulin+oligofructose mixture on calcium absorption was assessed using paired $t$-tests, using StatView v4.5.1 for Macintosh (Abacus Concepts Inc., Berkeley, CA). Statistical significance was taken at $P<0.05$ All data are presented as mean (standard deviation) unless otherwise stated.

\section{Ethical considerations}

The study received ethical approval from the Institutional Review Board of Baylor College of Medicine. Informed written consent was obtained from the subjects (where age-appropriate) and their parents.

Table 1. Demographic data for the subjects in Protocol I (placebo v. oligofructose) and Protocol II (placebo v. Synergy1)

\begin{tabular}{|c|c|c|c|}
\hline & Protocol I & Protocol II & $P$-value $\neq$ \\
\hline Number & 30 & 29 & \\
\hline Age (years)* & $12.1(0.7)$ & $11.8(0.8)$ & 0.12 \\
\hline Weight $(\mathrm{kg})^{*}$ & $42(9)$ & $46(9)$ & 0.14 \\
\hline Height $(\mathrm{cm})^{\star}$ & $152(8)$ & $154(6)$ & 0.24 \\
\hline Ethnicity (\%)† & & & $0.08 \S$ \\
\hline African-American & $27 \%$ & $7 \%$ & \\
\hline Hispanic & $13 \%$ & $28 \%$ & \\
\hline Caucasian & $57 \%$ & $52 \%$ & \\
\hline Asian/others & $3 \%$ & $14 \%$ & \\
\hline Pubertal status & & & $0.53 \S$ \\
\hline Premenarcheal (\%) & $67 \%$ & $59 \%$ & \\
\hline
\end{tabular}

${ }^{*}$ Mean (SD).

†Totals may not equal 100 , due to rounding.

$\ddagger$ Unpaired $t$-test, unless otherwise stated.

$\S$ Chi-squared test.

\section{Results}

Of the sixty subjects recruited, a total of fifty-nine completed the study. One subject in Protocol II defaulted from the second visit, and it was not possible to re-arrange her admission, so she was excluded from analysis. This was not related to intolerance of the study product. Demographics of the populations for the two protocols were similar (Table 1). The majority of subjects were Caucasian and premenarcheal.

\section{Compliance with non-digestible oligosaccharide}

Compliance was good, with a mean of $95.4 \%$ of the expected number of packets of the mixture inulin+oligofructose taken (SD $7.3 \%$, range $71 \%-100 \%$, median $100 \%$ ), and $95.2 \%$ of the expected number of packets of oligofructose taken (SD 7.9\%, range 68\%-100\%, median 100\%). All but four subjects achieved a compliance rate of at least $80 \%$ of the expected number of packets of oligosaccharides (two in Protocol I, and two in Protocol II). There was no difference in compliance between oligofructose and of the inulin+oligofructose mixture (unpaired $t$-test, $P=0.59$ ).

\section{Calcium intake}

There were no significant differences in calcium intake between the placebo and the oligofructose or the inulin+ oligofructose mixture phases of the study, either for Protocol I (oligofructose 1524 (265) $\mathrm{mg} / \mathrm{d} \quad v$. placebo 1611 (326) mg/d; $P=0.34$ ) or Protocol II (inulin+oligofructose mixture 1525 (282) mg/d $v$. placebo 1495 (280) mg/d; $P=0 \cdot 50)$.

\section{Calcium absorption}

In Protocol I, there was no significant difference in fractional calcium absorption on placebo $(31.8(9.3 \%))$ or on oligofructose $(31.8(10.0 \%) ; P=0.75)$. In Protocol II, calcium absorption on the inulin+oligofructose mixture was $38.2(9.8 \%)$, significantly greater than on placebo (32.3 (9.8\%), $P=0.007)$. Calcium absorption during the placebo period did not differ significantly between Protocol I and Protocol II $(P=0.97)$. The absolute calcium absorption (the product of fractional calcium absorption and dietary calcium intake) was significantly increased by the inulin+oligofructose mixture $(575 \quad(148) \mathrm{mg} / \mathrm{d} \quad$ v. 485 (154) $\mathrm{mg} / \mathrm{d}, \quad P=0.004)$, but not by oligofructose (489 (169) $\mathrm{mg} / \mathrm{d} v .490(153) \mathrm{mg} / \mathrm{d} ; P=0.99)$, in comparison with placebo.

\section{Urinary calcium excretion}

Calcium excretion during the $48 \mathrm{~h}$ study period was variable, and did not differ significantly between groups. In Protocol I, calcium excretion was 71 (48) $\mathrm{mg} / \mathrm{d}$ during the placebo period and $79(50) \mathrm{mg} / \mathrm{d}$ during the oligofructose period $(P=0 \cdot 26)$. In Protocol II, the corresponding values were $65(54) \mathrm{mg} / \mathrm{d}$ for placebo and $71(50) \mathrm{mg} / \mathrm{d}$ for the inulin+oligofructose mixture $(P=0.92)$. 


\section{Estimated calcium balance}

Net calcium balance was estimated by subtracting measured urinary calcium excretion and an estimate of endogenous fecal excretion, $1.4 \mathrm{mg} / \mathrm{kg}$ (Abrams et al. 1991) from the product of the fractional calcium absorption and the dietary calcium intake. This was similar during the sucrose and oligofructose periods of Protocol I (430.7 $(153.4) \mathrm{mg} / \mathrm{d} \quad v .438 .5 \quad(169.0) \mathrm{mg} / \mathrm{d} ; \quad P$-value=0.87). In Protocol II, estimated calcium balance was significantly greater during the inulin+oligofructose mixture period than the sucrose period $(511.4(151.4) \mathrm{mg} / \mathrm{d} \quad v .421 \cdot 1$ (154.0) $\mathrm{mg} / \mathrm{d} ; P$-value $=0.004)$.

\section{Discussion}

In this study, we examined the effect of 21 days' adaptation to modest amounts of two non-digestible oligosaccharides, oligofructose and an inulin+oligofructose mixture, on calcium absorption in girls at or near puberty who were consuming a diet containing the recommended dietary allowance of calcium. Calcium absorption, measured using a dual stable isotope method, was significantly higher when subjects consumed $8 \mathrm{~g} / \mathrm{d}$ of the inulin+oligofructose mixture than whilst consuming placebo. No significant benefit was seen from $8 \mathrm{~g} / \mathrm{d}$ of oligofructose.

The dual stable isotope method of evaluating calcium absorption has been discussed in detail elsewhere (Yergey et al. 1990; Yergey et al. 1994); and a $24 \mathrm{~h}$ urine collection is adequate to allow accurate measurement of calcium absorption (Yergey et al. 1994). Indeed, in some populations, as brief a collection as $12 \mathrm{~h}$ may be adequate (Hillman et al. 1988). In normal circumstances, very little calcium absorption occurs in the colon (Hillman et al. 1988); however, oligosaccharides may significantly increase colonic absorption of calcium (Van Loo et al. 1999). It has been argued that a longer urine collection is required to capture this late, colonic, phase of absorption (Barger-Lux et al. 1989; van den Heuvel et al. 1998). For this reason, we extended the urine collection in our study to $48 \mathrm{~h}$ after administration of the intravenous tracer, or at least $36 \mathrm{~h}$ after administration of the second dose of oral calcium tracer.

Three studies had evaluated the effects of different oligosaccharides on calcium absorption in humans, with conflicting results. Coudray et al. (1997) showed in a study of nine men that $40 \mathrm{~g} / \mathrm{d}$ of inulin significantly increased calcium absorption, measured by a metabolic balance, from $21.3 \%$ (SD 12.5\%) to $33.7 \%$ (SD 12.1). Van den Heuvel et al. (1998), however, found no effect of $15 \mathrm{~g} / \mathrm{d}$ inulin, oligofructose or galacto-oligosaccharides on calcium absorption in young men, using a dual-isotope tracer method. One criticism of this study was that urine was only collected for $24 \mathrm{~h}$, potentially missing the late colonic phase of absorption (Coudray \& FairweatherTait, 1998). Indeed, a subsequent study by the same group (van den Heuvel et al. 1999), using a $36 \mathrm{~h}$ urine collection, showed that $15 \mathrm{~g} / \mathrm{d}$ oligofructose significantly increased calcium absorption from $47.8 \%$ (SD 16.4) to $60 \cdot 1 \%$ (SD 17.2). Our data show a significant increase in calcium absorption in response to the consumption of $8 \mathrm{~g} / \mathrm{d}$ of an inulin+oligofructose mixture, but no beneficial effect of $8 \mathrm{~g} / \mathrm{d}$ of oligofructose. This suggests that this mixture may be a more potent promoter of calcium absorption than oligofructose.

The present study differs from previous studies in a number of important aspects. All previous studies have been very small, involving only nine to twelve male subjects, and used rather high intakes of oligosaccharides (15-40 g/d) (Coudray et al. 1997; van den Heuvel et al. 1998; van den Heuvel et al. 1999). The dose of oligosaccharides used in the current study was only $8 \mathrm{~g} / \mathrm{d}$. This compares to a typical dietary intake of $2.6 \mathrm{~g} / \mathrm{d}$ of inulin and $2.5 \mathrm{~g} / \mathrm{d}$ of oligofructose in the Western diet (Moshfegh et al. 1999), and well below the amount of oligosaccharides that may cause abdominal symptoms (Briet et al. 1995).

Previous studies have evaluated subjects with calcium intakes in the order of $800 \mathrm{mg} / \mathrm{d}$, well below the RDA for this age group of $1300 \mathrm{mg} / \mathrm{d}$ (Institute of Medicine Food and Nutrition Board's Standing Committee on the Scientific Evaluation of Dietary Intervals, 1997). Work by Matkovic \& Heaney (1992) has suggested that during the stage of life approaching and at the achievement of puberty, net calcium balance increases with increasing calcium intake, to a maximum of about $1200 \mathrm{mg} / \mathrm{d}$. Beyond this threshold, further increases in calcium intake do not improve calcium balance. Despite the fact that our subjects averaged total daily calcium intakes that achieved and even surpassed this threshold, a mixture of inulin+oligofructose significantly increased their absorption of calcium. It is not clear from our data whether the additional amount of absorbed calcium was utilized for bone mineral production; however, we did not find an increase in urinary calcium excretion that would have negated the increase in calcium absorption. The absolute increase in calcium absorption due to consumption of a mixture of inulin+oligofructose was approximately $90 \mathrm{mg} / \mathrm{d}$, which is, clinically, highly significant. If even part of this additional calcium was utilized for bone mineral production, it could lead to a significant increase in peak bone mineral density during this critical period. Preliminary data from ovariectomized rats show that not only did galacto-oligosaccharides increase calcium absorption, but the additional calcium absorption resulted in an increased bone mineral mass (Chonan et al. 1995). If this was the case in our study population, the results could have significant public health implications.

The effects of non-digestible oligosaccharides on more sophisticated measures of calcium metabolism and on bone mineral accretion rates will require further study, and were not the purpose of this study. Our findings, however, show that regular intake of modest amounts of a mixture of inulin+oligofructose significantly increases calcium absorption in girls at or near menarche, with adequate or high calcium intakes, without any compensatory increase in urinary calcium excretion.

\section{Acknowledgements}

The authors would like to thank Mercedes Villareal, Dorothy Powledge, Lily Liang, Dahlia Galicia, Lisa Turner, Chris Branner, Michele Brand and Yana Kriseman 
for their help with the study; and Leslie Loddeke for editorial assistance.

\section{References}

Abrams SA, Sidbury JB, Muenzer J, Esteban NV, Vieira NE \& Yergey AL (1991) Stable isotopic measurement of endogenous fecal calcium excretion in children. Journal of Pediatric Gastroenterology Nutrition 12, 469-473.

Abrams SA \& Stuff JE (1994) Calcium metabolism in girls: current dietary intakes lead to low rates of calcium absorption and retention during puberty. American Journal of Clinical Nutrition 60, 739-743.

Barger-Lux MJ, Heaney RP \& Recker RR (1989) Time course of calcium absorption in humans: evidence for a colonic component. Calcified Tissue International 44, 308-311.

Briet F, Achour L, Flourie B, Beaugerie L, Pellier P, Franchisseur C, Bornet F \& Rambaud JC (1995) Symptomatic response to varying levels of fructo-oligosaccharides consumed occasionally or regularly. European Journal of Clinical Nutrition 49 , 501-507.

Brommage R, Binacua C, Antille S \& Carrie AL (1993) Intestinal calcium absorption in rats is stimulated by dietary lactulose and other resistant sugars. Journal of Nutrition 123, 2186-2194.

Chan GM (1991) Dietary calcium and bone mineral status of children and adolescents. American Journal of Diseases of Children 145, 631-634.

Chonan O, Matsumoto K \& Watanuki M (1995) Effect of galactooligosaccharides on calcium absorption and preventing bone loss in ovariectomized rats. Bioscience Biotechnology and Biochemistry 59, 236-239.

Chonan O \& Watanuki M (1995) Effect of galactooligosaccharides on calcium absorption in rats. Journal of Nutritional Science and Vitaminology (Tokyo) 41, 95-104.

Coudray C, Bellanger J, Castiglia-Delavaud C, Rémésy C, Vermorel M \& Rayssignuier Y (1997) Effect of soluble or partly soluble dietary fibres supplementation on absorption and balance of calcium, magnesium, iron and zinc in healthy young men. European Journal of Clinical Nutrition 51, 375-380.

Coudray C \& Fairweather-Tait SJ (1998) Do oligosaccharides affect the intestinal absorption of calcium in humans? American Journal of Clinical Nutrition 68, 921-923.

Delzenne N, Aertssens J, Verplaetse H, Roccaro M \& Roberfroid M (1995) Effect of fermentable fructo-oligosaccharides on mineral, nitrogen and energy digestive balance in the rat. Life Sciences 57, 1579-1587.

Eastell R, Vieira NE, Yergey AL \& Riggs BL (1989) One-day test using stable isotopes to measure true fractional calcium absorption. Journal of Bone and Mineral Research 4, 463-468.

Eck LH \& Hackett-Renner C (1992) Calcium intake in youth: sex, age, and racial differences in NHANES II. Preventative Medicine 21, 473-482.

Greger JL (1999) Non-digestible carbohydrates and mineral bioavailability. Journal of Nutrition 129, 1434S-1435S.

Hillman LS, Tack E, Covell DG, Vieira NE \& Yergey AL (1988) Measurement of true calcium absorption in premature infants using intravenous ${ }^{46} \mathrm{Ca}$ and oral ${ }^{44} \mathrm{Ca}$. Pediatric Research 23, 589-594.

Institute of Medicine Food and Nutrition Board's Standing Committee on the Scientific Evaluation of Dietary Intervals (1997) Calcium. In Dietary Reference Intervals for Calcium, Phosphorus, Magnesium, Vitamin D and Fluoride, pp. 71-146 Washington, DC: National Academy Press.

Matkovic V (1992) Calcium and peak bone mass. Journal of Internal Medicine 231, 151-160.

Matkovic V \& Heaney RP (1992) Calcium balance during human growth: evidence for threshold behavior. American Journal of Clinical Nutrition 55, 992-996.

Moshfegh AJ, Friday JE, Goldman JP \& Ahuja JK (1999) Presence of inulin and oligofructose in the diets of Americans. Journal of Nutrition 129, 1407S-1411S.

Nieves JW, Golden AL, Siris E, Kelsey JL \& Lindsay R (1995) Teenage and current calcium intake are related to bone mineral density of the hip and forearm in women aged 30-39 years. American Journal of Epidemiology 141, 342-351.

Rémésy C, Levrat MA, Gamet L \& Demigne C (1993) Cecal fermentations in rats fed oligosaccharides (inulin) are modulated by dietary calcium level. American Journal of Physiology 264, G855-G862.

Roberfroid MB (1999) Concepts in functional foods: the case of inulin and oligofructose. Journal of Nutrition 129, 1398S-1401S.

Schulz AG, Van Amelsvoort JM \& Beynen AC (1993) Dietary native resistant starch but not retrograded resistant starch raises magnesium and calcium absorption in rats. Journal of Nutrition 123, 1724-1731.

van den Heuvel EG, Schaafsma G, Muys T \& van Dokkum W (1998) Non-digestible oligosaccharides do not interfere with calcium and nonheme-iron absorption in young, healthy men. American Journal of Clinical Nutrition 67, 445-451.

van den Heuvel EG, Muys T, van Dokkum W \& Schaafsma G (1999) Oligofructose stimulates calcium absorption in adolescents. American Journal of Clinical Nutrition 69, 544-548.

Van Loo J, Coussement P, De Leenheer L, Huybregs H \& Smits G (1995) On the presence of inulin and oligofructose as natural ingredients in the Western diet. Critical Reviews of Food Science and Nutrition 35, 525-552.

Van Loo J, Cummings J, Delzenne N, Englyst H, Franck A, Hopkins M, Kok N, Macfarlane G, Newton D, Quigley M, Roberfroid M, van Vliet T \& van den Heuvel E (1999) Functional food properties of non-digestible oligosaccharides: a consensus report from the ENDO project (DGXII AIRIICT94-1095). British Journal of Nutrition 81, 121-132.

Yergey AL, Vieira NE \& Hansen JW (1980) Isotope ratio measurements of urinary calcium with a thermal ionization probe in a quadrupole mass spectrometer. Analytical Chemistry 52, $1811-1814$.

Yergey AL, Abrams SA, Vieira NE, Eastell R, Hillman LS \& Covell DG (1990) Recent studies of human calcium metabolism using stable isotopic tracers. Canadian Journal of Physiology and Pharmacology 68, 973-976.

Yergey AL, Abrams SA, Vieira NE, Aldroubi A, Marini J \& Sidbury JB (1994) Determination of fractional absorption of dietary calcium in humans. Journal of Nutrition 124, 674-682. 